\title{
Effect of Charitable Giving : Donors' Choice of Governance
}

\author{
Dr Tamilchelvi FCCA, CA, MBA (Fin \& Invt), PhD \\ Senior lecturer in PSB Academy Singapore
}

\begin{abstract}
This study examines how the governance of the Non-Profit Organizations and Charities (NPOs) affect the charitable giving of donors using the regression model and comparing it with the structural equation model. Samples are collected in Singapore and donors' views are examined. To test the donors' choice of governance, compliance to governance is taken to be the dependent variable against four independent variable of corporate governance that is roles and responsibilities, information disclosure, accountability and board's processes. Donors largely agreed that these components are fundamental to good governance and are main contributors to their donations and trust; they would place with the charities and NPOs. Social responsibility and accountability seemed to have a negative influence on the compliance to governance as donors believe that compliance to such governance process will no longer be important if NPOs and charities are proven to be socially responsible and accountable.
\end{abstract}

Keywords: Charities and Non-profit organisations (NPOs), Corporate Governance, Donors, Compliance

\section{INTRODUCTION}

Corporate governance concerns with an involvement of one or more parties with organizational decision-making where they may not behave in the best interest of the organization and related stakeholders. The increased crisis last decade caused by scandalised companies whose notorious governance has evoked corporate failure, bankruptcies and loss in investor's confidence. This increases concern on corporate governance of government, top managers, business owners, investors and society bringing into the popularity of the SarbanesOxley Act (SOX). SOX has a good regulatory system for auditors of publicly-traded companies which made the most important changes in regulations governing the responsibilities of directors, officers and corporate transparency obligations. Moreover such scandals, lead to the society consolidation on ethical principles, and strong frameworks that reduces the risks of fraud and corporate scandals (Asha, 2012).

Charities and NPOs are organizations which operate on a not-for-profit basis, which are purpose - driven that carry out activities to achieve these purposes which benefit the public or its members.

Thomas Sprecher (2010) said that the structures and management bodies of non-profit organisations have to be scrutinised more stringently in terms of governance. It has been agreed and supported everywhere around the globe that governance is utmost important to the charities and Non-Profit Organisations. NPOs need not only be well governed, but need to be seen to be well governed. This is very important if they are to be continuously supported for funding by governments, corporations and private donors and to meet the heightened accountability and expectations from stakeholders. Quick spread of information through social media affects the way an organization is perceived, and it would be difficult to recruit quality board members, who may be concerned about public liability, (Deloitte LLP 2013). 
The most significant difference between the for-profit board and the NPO board is that NPO Board is mainly made of volunteers. Good and dedicated volunteers are the backbone for most NPOs at both operating and board levels. The volunteers are committed because of interests and beliefs, not compensation. Volunteer boards must be managed in a different way from compensated boards. Hence, to enforce and implement governance in NPOs and charities is difficult but it is pertinent as the funds are raised from the public.

This paper analyses whether the public and donors expect more governance from charities and NPOs in extending their donation where there are already stringent regulations in place or they believe charities and NPOs are over-regulated and total compliance is almost impossible.

The paper synthesises the literature on the factors affecting the governance in non-profit organisations and charities and develops the hypotheses that are tested through the use of advanced statistical analysis such structural equation modelling.

\section{LITERATURE REVIEW}

Berle and Means (1932), the pioneer in the contemporary thinking about corporate governance, has identified concepts which were developed from the growing separation of power between the executive management of the major public companies and their shareholders. Governance relates to the systems and processes in place to ensure the overall direction, effectiveness, supervision and accountability of an organisation.

Charities are also non-profit organizations which have philanthropic commitments and definite social purpose such as charitable services, educational, religious, or other activities serving the public interest, Stephen P. Osborne (2005). Non-profit organizations are very purpose driven. They are organized to serve some group which could be individuals or other organizations. Most of these charities are funded by public and the government, for some charitable course, Cornforth, C. (2003). Many of them are tax-exempt.

Most countries around the world have code of corporate governance for non-profit organizations and charities to help the NPO board members in their fiduciary duties, boost best practices in non-profit governance and enhance public confidence in these organizations.

Though there were specific policies set out in the constitution of these non-profit organisations and charities with regards to governance, public confidence is rocked by financial scandals involving non-profit organizations, Rhode \& Packel (2009).

The Singapore corporate governance is based on the Anglo-Saxon System which encompasses the capital market controls of managerial behaviour (Prowse, 1998). Singapore has developed a good reputation for sound government and has been rated highly for its efficiency, rule of law and lack of corruption by international rating agencies, such as IMD, Transparency International and PERC. Good governance has been a key factor to attract international attention. Being a country with multi-cultural, multi-racial and multi-lingual, Singapore's system of governance is unique and is shaped by the unique nation, unique environment and unique government.

Over the last decade, Singapore's NPO Sector has been shaken by many scandals related to lack of transparency and poor governance. Many NPOs and charities have been charged with multiple irregularities and mismanagement of funds, which proves bad governance, Presse (2005). 
In Singapore, the Charity Council has issued a code of governance since 2007 and developed it over the years. This constitutes, the roles of the board, their independence, bye-laws, distinction of duties, voting rights and policies on conflict of interest, staff appointment, asset management, fund-raising practises, transparency and disclosure requirement. It clearly states the accountability and responsibilities of the board. Besides this, a clear code of ethics and best practises are also recommended by various professional bodies and accounting firms. The council also established instruments such as online governance evaluation checklist and courses on board governance for non-profit organisations, Charity Council (2011).

However, the donors' choice on how much governance is required and what is required has not been measured. The expectations of the donors and the public have to be measured effectively to streamline the code of conduct of NPOs.

\section{Contributors of good governance - Donors' choice}

Studies have found a positive relationship between the board's governing good roles and responsibilities and non-profit organizational effectiveness (Preston and Brown, 2004). They believe that charitable organizations that have a better quality of governance will be better in gaining public trust, and, hence, will be in a better position to secure donations from the public Ostrower and Stone (2007) has illustrated governance focusing on boards of directors of NPOs. Indeed, many studies and surveys on NPOs' governance have concentrated on boards and their composition and the roles and responsibilities of their members of the board which leads to organisational effectiveness, Herman \& Renz, 2000; Callen, Klein, \& Tinkelman, 2003. Mostly NPOs governance is related to the board's legal authority to establish policies, make decisions on behalf of the organisation, and is accountable for the actions as a result of those policies and decisions, Sheilds (2007). This is one of the main factors influencing the funders and public in extending their funds to these organisations.

Governance Practices of National Nonprofit Bodies and National Networking Organisations in South Africa (2009) have identified seven characteristics of good governance sin NPOs and have included that accountability and respect for the various stakeholders as the main characteristics. It also prescribes that the social capital is built through social responsibility initiatives that respond to social, environmental and human rights issues, and ethical standards. NPOs are accountable to donors, beneficiaries and the broader public. They are intermediaries between donors and beneficiaries.

The nonprofit sector faces many ethical issues which include areas such as compensation; conflicts of interest; publications and solicitation; financial integrity; investment policies; and accountability and strategic management. These affects governance and social impact reporting which ultimately affect the overall credibility and accountability, (Bloomquist 2015). NPOs, even though consist of volunteers, they are still liable and socially accountable in order to gain the confidence of the donors and public, (Deloitte 2013).

According to Bain.com.(2017), the NPOs' abilities to raise private funding are affected by the donors' lack of confidence in the use of contributions and the unavailability of financial reports. Accountability and transparency are pertinent to enhance the relationships among NPOs, donors and volunteers. To strengthen donor confidence, NPOs need to regularly update donors with information about their contributions, the impact of those contributions on the beneficiaries and the organization's progress. 
Transparency is essential to the health of the nonprofit sector. Transparency gives openness when the NPOs share readily information about their programs (including goals, activities, and accomplishments) and finances with donors, funders, regulators, and the general public. This helps fundraising as donors are able to identify the NPOs which they want to support. Donors obtain greater satisfaction when they contribute to NPOs whose values are clear and sound. Donors want their charitable dollars to go to a legitimate course which is transparent, Bain.com. (2017).

NPO donors and the public expect total transparency which manifests more and more each year. The expected level of NPO transparency by donors is much higher than the minimum required by laws. People complain when they do not get their expected information. This lack of information creates distrust among donors and they may decide not to support the nonprofit organization, (Carlson 2011).

The board of a well-governed nonprofit organization will formulate key corporate policies and strategic goals, focusing both on short run and long run challenges and goals; see to the integrity of its internal systems and controls, and the accuracy of its financial statements. It also evaluates and manages risk. It helps to facilitate senior management, in order to run the operations well, (Rosenthal, 2017). Thus, Rosenthal 2017, believes board processes and structure plays a very important role in getting the investors (donors) to invest in the nonprofit organisatison.

According to Millesen (2016), effectiveness of the board affects its ability to receive donations. The key characteristics are having a clear mission and purpose; ability to perform key functions; strong practices, procedures, and policies; good people; and ability to mobilize staff and donors.

Hence, it has been identified that Board's Roles and Responsibilities; the non profits information disclosure and transparency; its social responsibility and accountability and good board processes, structure and characteristics make non-profits effective in the eyes of donors. Donors choose to donate to these non-profit organisations.

\section{Extension to the previous study}

In a previous study, Chokkalingam (2015), the above variables were tested based on various demographics including gender, education level and different characteristics of donors. Reliability analysis and descriptive analysis were performed. Hypotheses were tested and proven not significant. It has been said that donors believe that compliance to code of governance is important element in extending their donations. Donors of non-profits relate that they are influenced by the organisations' compliance to roles and responsibilities, compliance to board processes and structures, compliance to information disclosure and transparency and compliance to social responsibility and accountability.

In this study, the following independent variables and the dependent variable of compliance to code of Governance (Compliance) will be extended to further tests by applying the Multiple regression analysis and Structural Equation Modelling (SEM) Analysis.

- Shared Roles and Responsibilities of Charities and NPOs (Roles)

- Board Processes, Structure and characteristics (Board)

- Information Disclosure and Transparency (Disclosure)

- Social Responsibility and Accountability (Accountability) 


\section{DATA AND METHODOLOGY}

In this paper, the Singapore registered charities and non-profit organisations are classified into main four charitable organisations, Religion, Social Services, Health and Education. The donors are randomly sampled within these categories. Using the quota sampling, 400 donors were selected and response rate was about $60 \%$.

\section{Regression Analysis}

Multiple regression analysis is used in this study which involves in predicting a continuous dependent variable from a number of independent variables where,

$$
\mathbf{Y}=\mathbf{b}_{0}+\mathbf{b}_{1} \mathbf{X}_{1}+\mathbf{b}_{2} \mathbf{X}_{2}+\ldots \ldots \ldots \ldots \ldots \ldots+\mathbf{b}_{\mathbf{k}} \mathrm{Xk} \quad \text { (Colton, 2002) }
$$

The relationship between the $\mathrm{Y}$ and each of $\mathrm{X}$ is assumed to be linear. It also assumes the nonexistence of multicollinearity which means the independent variables are not related among themselves. To test this, the correlation coefficient is computed between each pair of independent variables.

The Pearson Correlation Coefficient tests if there is a linear relationship between the variables. According to Sarah Boslaugh (2013), to quantify the strength of the relationship, the correlation coefficient $(r)$ must be calculated. Its numerical value ranges from +1.0 to $-1.0 . r>0$ indicates positive linear relationship, $r<0$ indicates negative linear relationship while $r=0$ indicates no linear relationship.

\section{Structural Equation Modelling}

Structural Equation Modelling (SEM) is a multivariate analysis technique that tests and estimates causal relations using a combination of statistical data and qualitative causal assumptions. It has confirmatory (theory testing) and exploratory modelling (theory development. Here, confirmatory modelling is undertaken and starts out with a hypothesis that was represented in a model. The model is tested against the data collected to determine how well the model fits the data. The causal assumptions are put in the model usually have errors which can be tested against the data.

SEM allows constructing latent variables: variables that are not measured directly, but are gathered in the model from several measured statements. This predicts the unreliability of measurement in the model, which allows the structural relations between latent variables to be accurately estimated (Gramling, Maletta, Schneider \& Church 2004).

Here a path diagram is drawn on the variables which are inter-related. The variances and covariances of the variables are tested to fit the model. Parameter estimates and standard errors for the numerical coefficients in the linear equations are reported. Then, a decision is made on whether the model is a good fit. Fit shows how much the predicted covariances differ from the observed covariances. If there is small squared differences (residuals) indicate an acceptable fit that is, the model is plausible and cannot be rejected.

\section{Regression Analysis}

\section{EMPIRICAL RESULTS}

In the table 4.1 below, the four different variables such as roles, board, disclosure and accountability is tested to know their influence on the dependent variable compliance. The Pearson Correlation Coefficient shows that all the variables have significant relationship with the compliance to code of governance and the relationship is positive. The F test looks at how 
the model fits. Since the significance level (sig.) is less than 0.05 for all the variables, they are fitting the model very well.

$\mathrm{R}^{2}$ is to see how close the data are to the fitted to regression line. It is the percentage of the response variable variation that is explained by a linear model. It can also be depicted as:

$\mathrm{R}^{2}=$ Explained variation / Total variation

$\mathrm{R}^{2}$ is always between 0 and $100 \%$ :

- $0 \%$ indicates that the model explains none of the variability of the response data around its mean.

- $100 \%$ indicates that the model explains all the variability of the response data around its mean.

In general, the higher the $\mathrm{R}^{2}$, the better the model fits your data. Here in the Table 4.1 , The $\mathrm{R}^{2}$ is $45.6 \%$ which means the variance in the compliance code of governance is explained. The other $54.4 \%$ is unexplained which means there could other variables which might be omitted from the model.

According to Colton and Bower (2002), it is okay to have a low $\mathrm{R}^{2}$ values. In certain field, it is expected to have a low $\mathrm{R}^{2}$. For example, any field that attempts to predict human behaviour, such as psychology and fields within social sciences, typically has $\mathrm{R}^{2}$ values lower than $50 \%$. Humans are simply harder to predict than physical processes. Furthermore, if $\mathrm{R}^{2}$ value is low but has statistically significant predictors, then important conclusions on how changes in the predictor values are associated with changes in the response value is drawn. Regardless of the $\mathrm{R}^{2}$, the significant coefficients still represent the mean change in the response for one unit of change in the predictor while holding other predictors in the model constant.

The adjusted $\mathrm{R}^{2}$ is a measure to assess the contribution to the new variable added to the model. If more variables are added $\mathrm{R}^{2}$ will increase but here $\mathrm{R}^{2}$ in this model does not increase. At the bottom part of the table 4.1, the unstandardized coefficient shows that if roles increase by one unit compliance increase by 0.338 ,with board, it increases by 0.208 , and with disclosure, it increases by 0.273 , however if there is one unit increase in accountability, it reduces compliance by -0.121 . All variables proves the significant relationship as the sig. level is less than 0.05 , however accountability shows a low significance. Hence, we cannot proof that the statement on one unit of increase in accountability decreases compliance by -0.121 .

Beta (standardised regression coefficients) measures how strongly each predictor variable (roles, board, disclosure and accountability) influences the dependent (compliance) variable. The beta is measured in units of standard deviation. In the table below, under roles the beta value 0.388 a beta value which indicates that a change of one standard deviation in the roles will result in a change of 0.388 standard deviations in compliance. Thus, the higher the beta value the greater the impact of the predictor variable on the dependent variable. Thus, roles have the highest influence on compliance to code of governance, followed by disclosure (0.274), and then board (0.202). However, accountability shows a negative influence on compliance to code of governance, that is, the lower accountability means higher compliance.

When variables are highly correlated, they have multicollinearity. When variables are highly correlated in a multiple regression analysis it is difficult to identify the unique contribution of each variable in predicting the dependent variable because the highly correlated variables are predicting the same variance in the dependent variable. According to some statisticians, 
correlations above 0.70 indicate multicollinearity, and others say that correlations above 0.90 indicate multicollinearity. Multicollinearity exists when Tolerance is below 0.1; and VIF is greater than 10 or an average much greater than 1 . In this case, there is no multicollinearity. Hence, the data is not spurious.

Table 4.1 - General regression

\begin{tabular}{llrrrrr}
\hline & & COMPLIANCE & ROLES & BOARD & DISCLOSURE & ACCOUNTABILITY \\
\hline Pearson Correlation & COMPLIANCE & 1.000 & .627 & .572 & .566 & .434 \\
& ROLES & .627 & 1.000 & .681 & .649 & .576 \\
& BOARD & .572 & .681 & 1.000 & .702 & .655 \\
& DISCLOSURE & .566 & .649 & .702 & 1.000 & .767 \\
Sig. (1-tailed) & ACCOUNTABILITY & .434 & .576 & .655 & .767 & 1.000 \\
& COMPLIANCE & .000 & .000 & .000 & .000 \\
& ROLES & .000 &. & .000 & .000 & .000 \\
& BOARD & .000 & .000 &. & .000 & .000 \\
& DISCLOSURE & .000 & .000 & .000 & .000 \\
& ACCOUNTABILITY & .000 & .000 & .000 & .000 &. \\
\hline
\end{tabular}

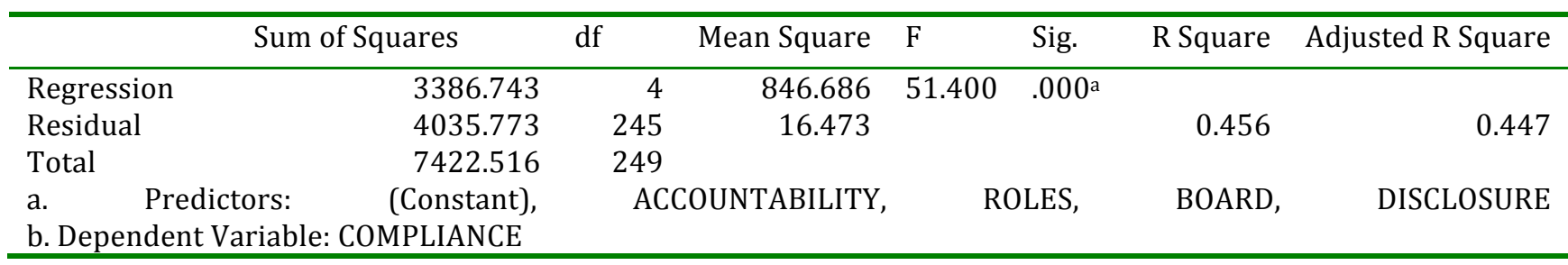

\begin{tabular}{|c|c|c|c|c|c|c|c|}
\hline & \multicolumn{2}{|c|}{$\begin{array}{l}\text { Unstandardized } \\
\text { Coefficients }\end{array}$} & \multirow{2}{*}{$\begin{array}{r}\text { Standardized } \\
\text { Coefficients } \\
\text { Beta }\end{array}$} & \multirow[t]{2}{*}{$\mathrm{t}$} & \multirow[t]{2}{*}{ Sig. } & \multicolumn{2}{|c|}{$\begin{array}{r}\text { Collinearity } \\
\text { Statistics }\end{array}$} \\
\hline & $\mathrm{B}$ & Std. Error & & & & Tolerance & VIF \\
\hline (Constant) & 11.944 & 1.732 & & 6.897 & 0.000 & & \\
\hline ROLES & 0.338 & 0.060 & 0.388 & 5.681 & 0.000 & 0.477 & 2.097 \\
\hline BOARD & 0.208 & 0.076 & 0.202 & 2.714 & 0.007 & 0.401 & 2.491 \\
\hline DISCLOSURE & 0.273 & 0.083 & 0.274 & 3.294 & 0.001 & 0.321 & 3.115 \\
\hline ACCOUNTABILITY & -0.121 & 0.070 & -0.132 & -1.730 & 0.085 & 0.383 & 2.610 \\
\hline a. Dependent Varial & ANCE & & & & & & \\
\hline
\end{tabular}

A study is made on the contrasting relationship between compliance and other variables relating to different kinds of donors so that the pattern, behaviour and properties of the data collected can be studied accurately.

We select a regression analysis on the religious donors is selected as they seemed to be largest in the sample size (about 60\%) and religious organisations seemed to be more influential and emotionally linked as compared to other charities and NPOs.

The significance level for all the variables for roles, board, disclosure and accountability is less than 0.05; hence they are significant correlation to the compliance to code of governance for religious donors. The $\mathrm{R}^{2}$ is $45.8 \%$ which means the variance of the compliance is explained for religious donors.

At the bottom part of the table 4.2, the unstandardized coefficient shows that if roles increase by one unit compliance increase by 0.252 ,with board, it increases by 0.238 , and with disclosure, it increases by 0.346 , however if there is one unit increase in accountability, it reduces compliance by -0.113 . All variables proves the significant relationship as the sig. level is less than 0.05, however accountability no significance. Hence, we cannot proof that the statement on one unit of increase in accountability decreases compliance by -0.113 . There is no 
multicollinearity as tolerance is more than 0.1 ; and VIF is lesser than 10 . The beta coefficient in the table below shows that, disclosure $(0.329)$ has the highest influence on compliance to code of governance for religious donors, followed by roles (0.281), and then board (0.237). However, accountability shows a negative influence on compliance to code of governance, that is, the lower accountability means higher compliance. Thus, we could conclude that disclosure and transparency seemed more important for religious donors.

Table 4.2 - Regression for Donors donating to Religious organizations

\begin{tabular}{lrrr}
\hline & Mean & Std. Deviation & $\mathrm{N}$ \\
COMPLIANCE & 35.4429 & 5.79167 & 140 \\
ROLES & 33.8071 & 6.45393 & 140 \\
BOARD & 32.4071 & 5.77379 & 140 \\
DISCLOSURE & 32.9000 & 5.49990 & 140 \\
ACCOUNTABILITY & 33.3143 & 6.19943 & 140 \\
a. Selecting only cases for which DONOR CHOICE = RELIGIOUS & & \\
\hline
\end{tabular}

\begin{tabular}{|c|c|c|c|c|c|c|}
\hline & & COMPLIANCE & ROLES & $\begin{array}{l}\text { BOAR } \\
\text { D }\end{array}$ & DISCLOSURE & ACCOUNTABILITY \\
\hline \multirow{5}{*}{$\begin{array}{l}\text { Pearson } \\
\text { Correlation }\end{array}$} & COMPLIANCE & 1.000 & 0.616 & 0.596 & 0.604 & 0.459 \\
\hline & ROLES & 0.616 & 1.000 & 0.738 & 0.716 & 0.625 \\
\hline & BOARD & 0.596 & 0.738 & 1.000 & 0.697 & 0.644 \\
\hline & DISCLOSURE & 0.604 & 0.716 & 0.697 & 1.000 & 0.762 \\
\hline & ACCOUNTABILITY & 0.459 & 0.625 & 0.644 & 0.762 & 1.000 \\
\hline \multirow[t]{5}{*}{ Sig. (1-tailed) } & COMPLIANCE & . & 0.000 & 0.000 & 0.000 & 0.000 \\
\hline & ROLES & 0.000 & . & 0.000 & 0.000 & 0.000 \\
\hline & BOARD & 0.000 & 0.000 & . & 0.000 & 0.000 \\
\hline & DISCLOSURE & 0.000 & 0.000 & 0.000 & & 0.000 \\
\hline & ACCOUNTABILITY & 0.000 & 0.000 & 0.000 & 0.000 & . \\
\hline
\end{tabular}

\begin{tabular}{|c|c|c|c|c|c|c|c|c|}
\hline \multicolumn{2}{|c|}{ Sum of Squares } & df & Mean Square & $\mathrm{F}$ & Sig. & R Square & \multicolumn{2}{|c|}{ Adjusted R Square } \\
\hline Regression & 2135.152 & 4 & 533.788 & 28.512 & $.000^{\mathrm{a}}$ & & & \\
\hline Residual & 2527.391 & 135 & 18.721 & & & 0.458 & & 0.442 \\
\hline \multirow[t]{3}{*}{ Total } & 4662.543 & 139 & & & & & & \\
\hline & & & $\begin{array}{l}\text { tandardized } \\
\text { Coefficients }\end{array}$ & $\begin{array}{l}\text { andardized } \\
\text { Coefficients }\end{array}$ & $\mathrm{t}$ & Sig. & Coll & $\begin{array}{l}\text { earity } \\
\text { tistics }\end{array}$ \\
\hline & B & Std. I & rror & eta & & & Tolerance & VIF \\
\hline (Constant) & 11.559 & & 2.368 & & 4.881 & 0.000 & & \\
\hline ROLES & 0.252 & & 0.093 & 0.281 & 2.715 & 0.007 & 0.375 & 2.670 \\
\hline BOARD & 0.238 & & 0.103 & 0.237 & 2.318 & 0.022 & 0.383 & 2.610 \\
\hline DISCLOSURE & 0.346 & & 0.119 & 0.329 & 2.898 & 0.004 & 0.312 & 3.207 \\
\hline ACCOUNTABILITY & -0.113 & & 0.094 & -0.120 & -1.191 & 0.236 & 0.393 & 2.546 \\
\hline $\begin{array}{l}\text { a. } \\
\text { b. Selecting only cas }\end{array}$ & $\begin{array}{r}\text { Depender } \\
\text { for which } D\end{array}$ & t & $\mathrm{HOICE}=\mathrm{RELIG}$ & $\begin{array}{l}\text { Variable: } \\
\text { JUS }\end{array}$ & & & OMPLIANCE & \\
\hline
\end{tabular}

\section{Structural Equation Modelling (SEM) Analysis}

Figure 4.1 shows the theoretical model. In every manifest variable (statement) the error occurs due to the answering pattern of the respondents or donors. These are to be filtered out before attempting to fit a model. The figure below does this process. All the variables such as roles, board, disclosure and transparency are captured in latent form (after removal of error). The model built with these latent variables will be producing better $\mathrm{R}^{2}$ and lower root, mean, 
square, error approximation (RMSEA). According to literatures, RMSEA if less than 5\%, it is good, up to $8 \%$ it is acceptable and more than $8 \%$, it is not acceptable. Table 4.5 , shows the model fit indices which for this measurement model fit well and this is done before the error removal. The $\mathrm{R}^{2}$ produced by the regression coefficient table 4.1 , shows $45.6 \%$ but the table 4.3 produced by the SEM analysis shows $60 \%$. The model has improved under the SEM analysis.

Table 4.3 - Model fit before error removal

\begin{tabular}{rrrrr}
\hline GFI & AGFI & CFI & $\mathrm{R}^{2}$ & RMSEA \\
\hline 0.632 & 0.597 & 0.774 & 0.6 & 0.077 \\
\hline
\end{tabular}

Figure 4.1 Theoretical Model of the Variables

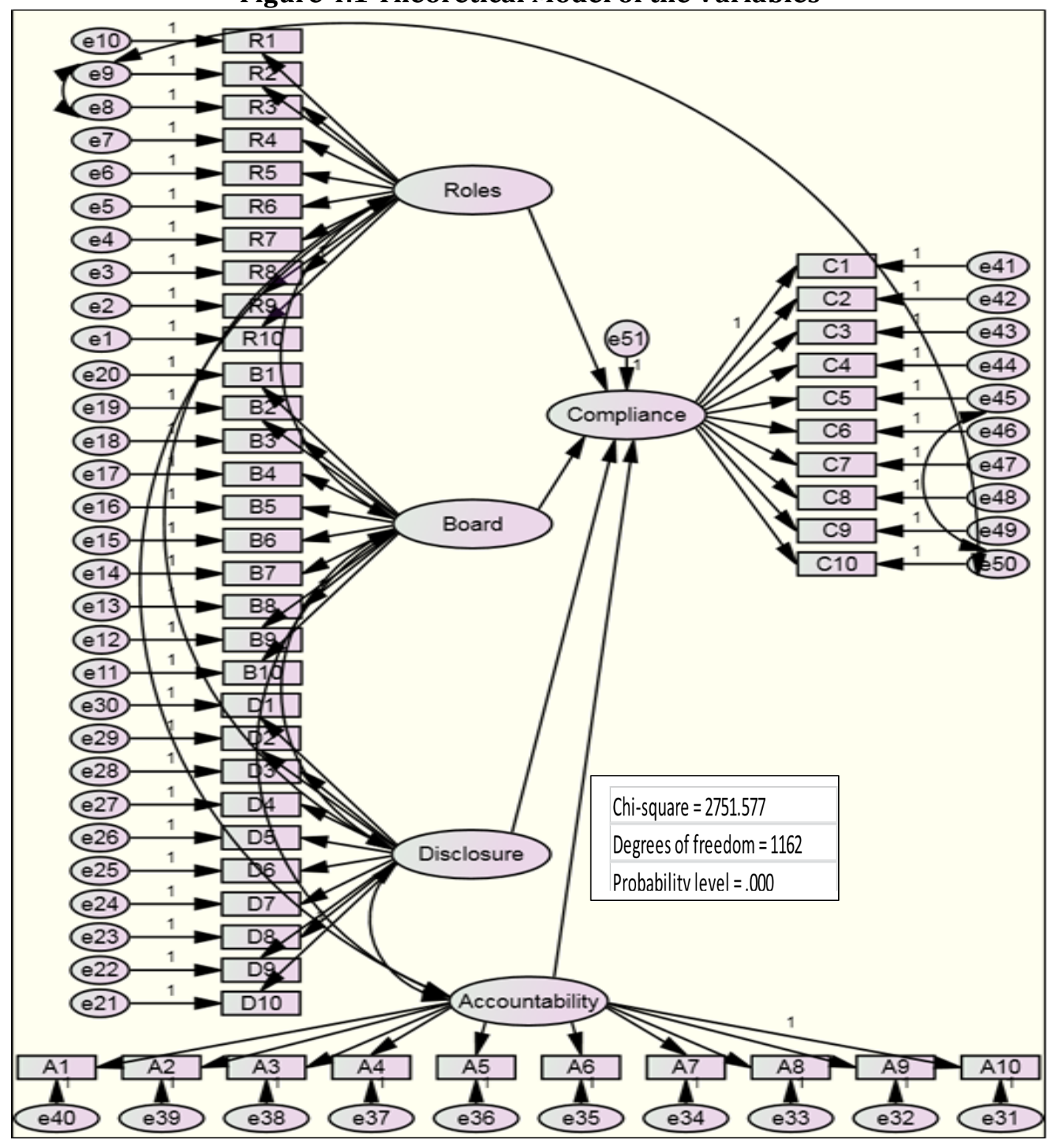

The figure 4.2 below shows the parameter in empirical values, mean, variance; co variance and unstandardised coefficient of regression are incorporated in the figure. These figures are obtained after filtering the errors form the manifest variables. The structural model is built with compliance as endogenous variable F5 (dependent variable in regression model). The four exogenous variables are roles F1, board F2, disclosure F3 and accountability F4 (independent variables in the latent figure). Table 4.4 shows that 1 unit of Roles F1 increases compliance F5 by 0.383 , Board F2 increases F5 by 0.297 , and disclosure F3 increase F5 by 
0.358 and accountability F4 decreases F5 by 0.364 which is a negative influence. All four exogenous variables influence the endogenous variable significantly in the perception of donors as the $\mathrm{P}$ value is below 0.05 . The output is not far different from the results shown in the regression model in Table 4.1 .

Table 4.4 regression weight of the four variables

\begin{tabular}{rllrrrr}
\hline & \multicolumn{4}{c}{ Estimate } & S.E. & C.R. \\
\hline F5 & $<---$ & F1 & 0.383 & 0.125 & 3.061 & 0.002 \\
F5 & F2 & F3 & 0.297 & 0.11 & 2.7 & 0.007 \\
F5 & $<---$ & 0.358 & 0.157 & 2.287 & 0.022 \\
F5 & $<---$ & F4 & -0.364 & 0.153 & -2.374 & 0.018 \\
\hline
\end{tabular}

The standardised coefficient values in the respective latent variable path are shown by Figure 4.3. Standardised coefficient will show the sensitivity of exogenous variables with endogenous variables but they will never give which variable is more influential or sensitive. This problem could be overcome by the standardisation process. The standardised coefficient is shown in the Figure below. The RMSEA is below $8 \%$ which is within acceptable level. To reduce the RMSEA, modification indices technique is used. The basic assumption in any statistical analysis is the uncorrelated item at errors. In other words, the errors are independent for instance, error 50 and error 9 should be independent as per theory, however, in this particular analysis, when modification indices are set at 50, the structural model indicate the dependence of e9 and e50. If they are linked by connecting them, the error will come down to better acceptable level and RMSEA improves as per table 4.5. Hence, 3 set of errors e9-e50, e50-e45 and e9-e8 are connected to improve the model.

Table 4.5 - Model fit after the error is filtered

\begin{tabular}{rrrrr}
\hline GFI & AGFI & CFI & R $^{2}$ & RMSEA \\
\hline 0.656 & 0.622 & 0.791 & 0.6 & 0.074 \\
\hline
\end{tabular}


Figure 4.2 unstandardized coefficients of the variables

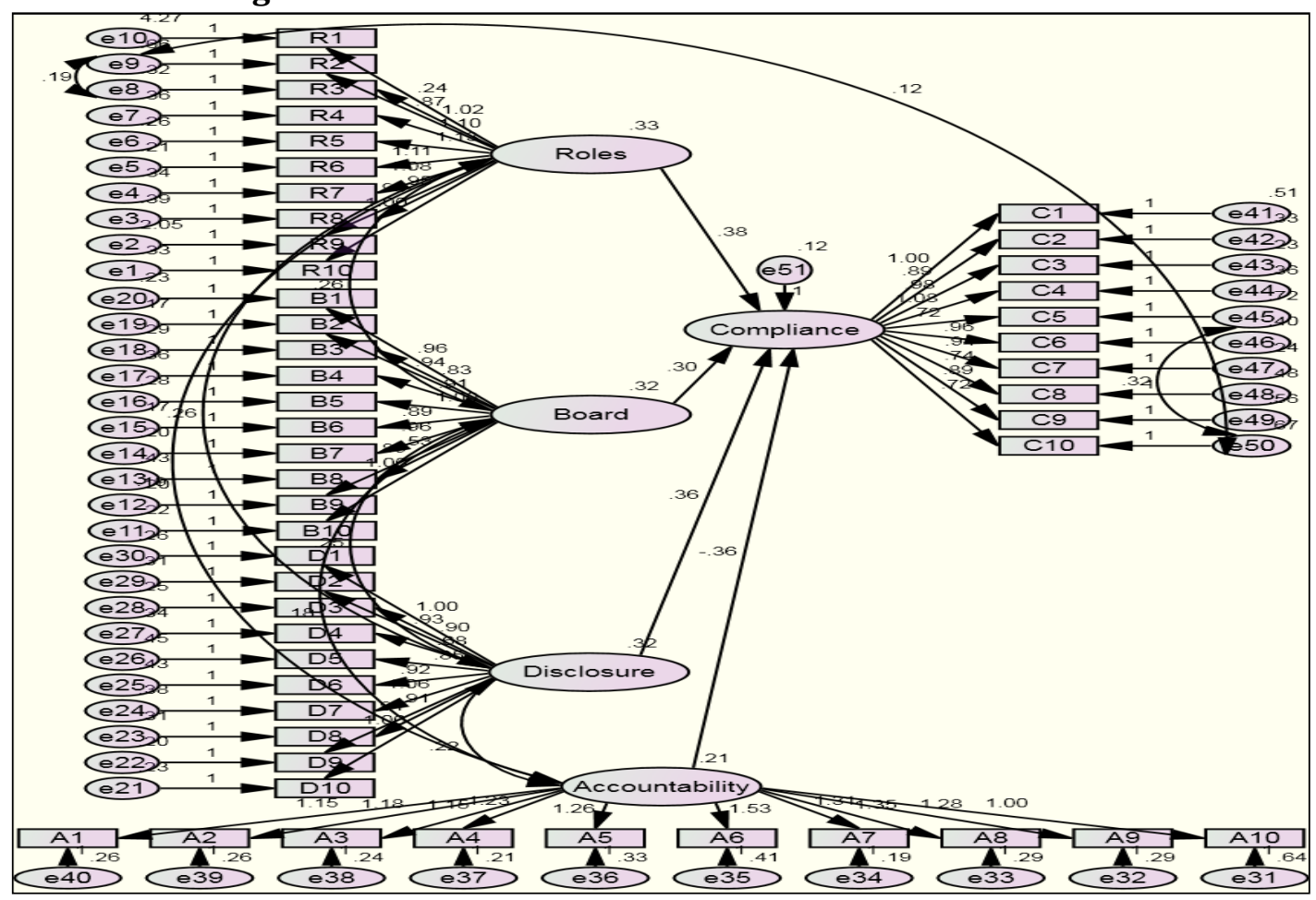

Figure 4.3 standardized coefficients of the variables

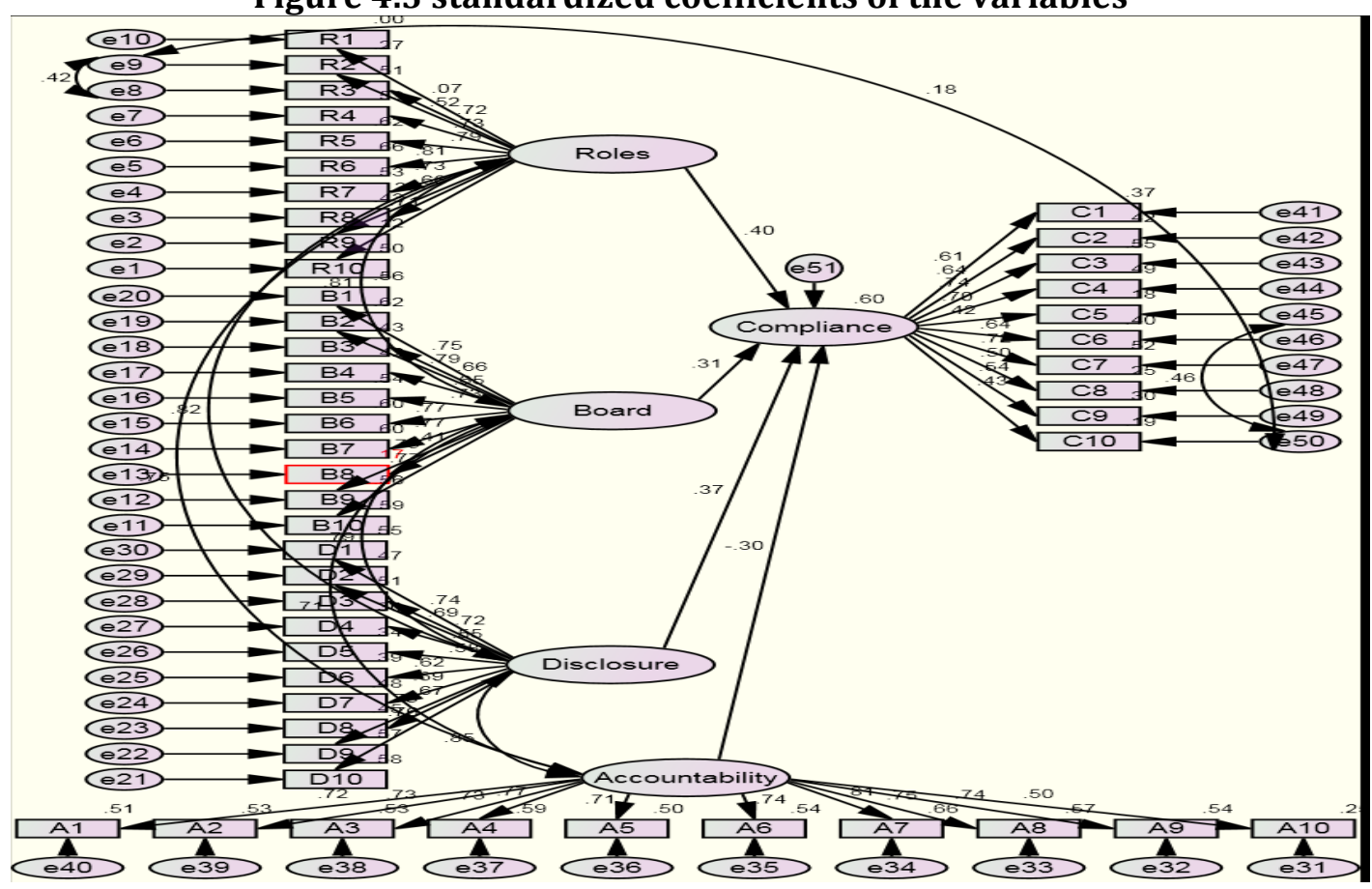

\section{DISCUSSION}

Most of the previous studies made in other parts of the world, had relied on limited traditional testing procedures like Cronbach alpha coefficient and factor analysis. However, this study extended to the model testing and path analysis in SEM, moreover, it has been done specifically to Singapore which is one of the first few researches. It would definitely contribute to the literature.

From the SEM Path analysis, all five hypotheses related to the influence of factors influencing the donors in terms of compliance to governance have been accepted. Strong statistical 
evidence was found in the model fit with a significance level of less than 0.05 . In the regression model, the $\mathrm{R}^{2}$ was $45.6 \%$ which a significant level according to many literatures. When this model was represented in the SEM path analysis the $\mathrm{R}^{2}$ was improved to be $60 \%$, this is a very significant level in social sciences. Donors believe that Compliance to code of governance is important element to their contributions.

\section{CONCLUSION}

The research has identified that donors of the charities and NPOs in Singapore are aware of how they have been governed and given a good mandate that they are well-run. Donors also believe that the board of the charities and NPOs is well-aware of their responsibilities and roles, well-laid policies are set, policymakers are mostly transparent and are socially responsible to the stakeholders and community. Hence, Donors perceive that Shared Roles and Responsibilities of Charities and NPOs; Board Processes, Structure and characteristics; Information Disclosure and Transparency and Social Responsibility and Accountability are fundamental components to a good governance and these contributors to their donations and trust, they would place with the charities and NPOs.

Social responsibility and accountability seemed to have a negative influence on the compliance to code of governance which is illustrated through the SEM Analysis. If companies are socially responsible and accountable, donors believe they need not be compiling to the code of governance. Charities and NPOs which are openly made accountable and gives back to society (approved by society), need not proof themselves based on their compliance to code of governance. This finding seemed quite remarkable on the part of the donors.

\section{References}

Asha, Stewart, J. F, Sulaiman. A, Ng.C (2012), Corporate Disclosure on the Internet: The case of Australian State Government Department, Australian Journal of Public Adminstration, 7/(4), 440-456

Bain.com. (2017). Design Principles for a Robust Operating Model. [online] Available at: http://www.bain.com/publications/articles/design-principles-for-a-robust-operating-model.aspx

Berle, A. A and means, G.C (1932) The Modern Corporation and Private Property, New York: Macmillan

Bloomquist, K. (2015). Radicalizing Reformation in North America Today?. Dialog, 54(4), pp.309-313.

Boslaugh, S. (2013). Statistics in a Nutshell. 1st ed. Beijing u.a.: O'Reilly.

Callen, J., Klein, A. and Tinkelman, D. (2003). Board Composition, Committees, and Organizational Efficiency: The Case of Nonprofits. Nonprofit and Voluntary Sector Quarterly, 32(4), pp.493-520.

Carlson, D. (2011). Trends and Innovations in Public Policy Analysis. Policy Studies Journal, 39, pp.13-26.

Charities.gov.sg. (2011). Archived Press Releases. [online] Available at:

https://www.charities.gov.sg/Publications/Pages/Archived-Press-Releases.aspx

Chokkalingam, T. and Ramachandran, T. (2015). The Perception of Donors on Existing Regulations and Code of Governance in Singapore on Charities and Non-Profit Organizations - A Conceptual Study. Asian Social Science, 11(9).

Colton, James A and Bower, Keith M.(2002), Some Misconceptions about R2 - Minitab. EXTRAOrdinary Sense (ISSSP Newsletter), August 2002

Cornforth, C. (2003), The Governance of Public and Non-Profit Organisations, What do boards do? Routledge, London.

Deloitte (2013), The Effective Not-for-Profit Board A value-driving force, 5-26

Gramling, A. A., Maletta, M. J., Schneider, A., \& Church, B. K. (2004). The role of the internal audit function in corporate governance: A synthesis of the extant internal auditing literature and directions for future research. Journal of Accounting Literature, 23, 194-244. 
Herman, R. and Renz, D. (2000). Board Practices of Especially Effective and Less Effective Local Nonprofit Organizations. The American Review of Public Administration, 30(2), pp.146-160.

McCabe, A. (2009). Governance Practices of National Nonprofit Bodies and National Networking Organisations in South Africa Nonprofit Organisations: Principles and Practices. Community Development Journal, 45(1), pp.138140.

Millesen, Judith L. Miller( 2016), Understanding the Behavior of Nonprofit Boards of Directors: A Theory-Based Approach [online] Available at: http://journals.sagepub.com/doi/abs/10.1177/0899764003257463

Laursen, G. and Thorlund, J. (2010). Business analytics. 1st ed. Hoboken, N.J.: Wiley.

Preston, J. and Brown, W. (2004). Commitment and performance of nonprofit board members. Nonprofit Management and Leadership, 15(2), pp.221-238.

Prowse, S. (1998). Angel investors and the market for angel investments. Journal of Banking \& Finance, 22(6-8), pp.785-792.

Rhode, D. and Packel, A. (n.d.) (2010) Diversity on Corporate Boards: How Much difference Does Difference Make? SSRN Electronic Journal.

Rosenthal, Lesley (2012), Nonprofit Corporate Governance: The Board's Role. [online] Available at: https://corpgov.law.harvard.edu/2012/04/15/nonprofit-corporate-governance-

Shields, T. (2007). Governance as Leadership: Reframing the Work of Nonprofit Boards20074Richard P. Chait, William P. Ryan, Barbara E. Taylor. Governance as Leadership: Reframing the Work of Nonprofit Boards. New Jersey: Wiley \& BoardSource 2005. 198 pp. \$30 US (hardcover), ISBN: 0-471-68420-1. Leadership \& Organization Development Journal, 28(2), pp.191-192.

Stephen P. Osborne (2005) , Chris Cornforth- "The Governance of Public and Non-Profit Organisations"

Stone, M. and Ostrower, F. (2007). Acting in the Public Interest? Another Look at Research on Nonprofit Governance. Nonprofit and Voluntary Sector Quarterly, 36(3), pp.416-438.

Thomas Sprecher (2010), Switzerland: the Swiss Foundation Code 2009-from corporate governance to foundation governance; Trusts \& Trustees (2010) 16 (6): 523-532. 